\title{
Composição química de diferentes fontes de fósforo e deposição de metais pesados em tecidos de suínos
}

[Chemical composition of different phosphorus sources and heavy metal deposition in tissues of swines]

\author{
A.O. Teixeira ${ }^{1}$, D.C. Lopes $^{2}$, M.C.T. Ribeiro ${ }^{3}$, J.B. Lopes $^{4}$, V.P.A. Ferreira ${ }^{5}$, \\ D.M.S.S. Vitti $^{6}$, J.A. Moreira ${ }^{6}$, S.M. Pena ${ }^{3}$ \\ ${ }^{1}$ Zootecnista \\ ${ }^{2}$ Universidade Federal de Viçosa - Viçosa, MG \\ ${ }^{3}$ Estudante de graduação - Universidade Federal de Viçosa - Viçosa, MG \\ ${ }^{4}$ Universidade Federal do Piauí - Teresina, PI \\ ${ }^{5}$ Faculdade de Estudos Administrativos de Minas Gerais - Belo Horizonte, MG \\ ${ }^{6}$ Centro de Energia Nuclear na Agricultura - Universidade de São Paulo - Piracicaba, SP
}

\begin{abstract}
RESUMO
Foram utilizados 112 leitões com peso inicial de $28,68 \mathrm{~kg}$, distribuídos em blocos ao acaso, em esquema fatorial $8 \times 2$ (oito tratamentos $\mathrm{x}$ dois sexos), sete repetições e dois animais por baia. As dietas foram formuladas com base no fósforo total, sendo estas à base de milho e de farelo de soja. $\mathrm{O}$ fósforo foi suplementado utilizando-se os fosfatos: bicálcico (FBC); monobicálcico (MBC); supertriplo (ST); supersimples (SS); rocha Catalão (ROCHA); mistura de fontes (MIST) e ácido fosfórico (AcF); e dietacontrole, sem o fósforo suplementar (CONT). Avaliou-se previamente a composição química de amostras de fontes de fósforo disponíveis no mercado. Os fosfatos $\mathrm{MBC}, \mathrm{FBC}$ e AcF apresentaram baixo nível de contaminação por metais pesados. Observou-se variação no teor de metais pesados entre as marcas comerciais de supertriplo. O consumo do fosfato resultou em acúmulo de cobre nos músculos. A dietacontrole provocou acúmulo de chumbo e zinco no fígado, e a mistura de fontes e supertriplo ocasionou acúmulo de cádmio no fígado. A utilização de fontes alternativas de fósforo menos elaboradas influenciou a deposição de minerais no fígado e nos músculos dos suínos.
\end{abstract}

Palavras-chave: fígado, músculo, metais pesados, nutrição, suíno

\begin{abstract}
One hundred twelve pigs averaging weight of $28.68 \mathrm{~kg}$, were allotted to a completely randomized blocks with seven replicates of two animals per box. The treatments consisted in factorial $8 \times 2$ (eight phosphorus sources $x$ two sexes). The experimental diets were formulated based on corn and soybean meal and the phosphorus was supplemented through phosphate dicalcium (FBC), monodicalcium (MBC), triple superphosphate (ST), simple superphosphate (SS), Catalão rock (ROCHA), mixture of sources (MIST), and phosphoric acid (AcF) in addition to a control diet without supplemental phosphous (CONT). Samples of phosphorus sources available in the market were evaluated for particle size and chemical composition. The MBC, FBC and AcF showed a low level of heavy metal contamination, but a variation in the heavy metal composition for ST was observed. Swines fed on CONT diet showed lead and zinc accumulation in the liver. Swines fed on triple superphosphate and mixture of sources diets showed cadmium accumulation in the liver. Swine fed on ST diet showed copper accumulation in the muscles.
\end{abstract}

Apoio financeiro parcial: Bunge Fertilizantes SA.

Recebido para publicação em 2 de outubro de 2003

Recebido para publicação, após modificações, em 16 de agosto de 2004

*Endereço para correspondência (mailing address)

Rua Guaporé, 117D/104, Centro

89801-100 - Chapecó, SC

E-mail: alotei@bol.com.br 
Swine diets formulated with alternative and less elaborated sources of phosphorus caused liver and muscles deposition of minerals.

Keywords: liver, muscle, heavy metal, nutrition, swine

\section{INTRODUÇÃO}

O fósforo é um mineral essencial ao organismo animal, pois desempenha múltiplas e importantes funções (participa na constituição da matriz óssea, dos fosfolipídios da membrana celular, da estrutura dos ácidos nucléicos e de sistemas enzimáticos) que o tornam alvo de atenção na formulação de rações. Ele representa de 20 a $50 \%$ dos custos com suplementos minerais e vitamínicos e até $1,5 \%$ dos gastos totais com alimentação de suínos (Lopes, 1998).

Algumas indústrias formuladoras de suplemento mineral e/ou de rações têm utilizado estratégias, como o uso de fontes alternativas de fósforo, a inclusão de matérias-primas com menor custo e ricas em fósforo e a adição de enzima fitase exógena nas dietas, com o objetivo de aumentar a disponibilidade do fósforo fítico presente nos alimentos. Alguns nutricionistas recomendam a redução da suplementação com fósforo inorgânico na fase de terminação, ficando a ração com valores abaixo das exigências do animal. Entretanto, algumas técnicas podem provocar perda na qualidade física, química $\mathrm{e}$ microbiológica da ração, comprometendo o metabolismo e a estrutura corporal dos animais em razão do desequilíbrio entre os minerais, da inclusão de patógenos e da contaminação por elementos tóxicos, o que, conseqüentemente, prejudica o desempenho produtivo e reprodutivo dos animais.

Para obtenção do fosfato de uso alimentar, é necessária a transformação da fluorapatita (13 a $14 \% \mathrm{P}, 3$ a $4 \% \mathrm{~F}$ ) em fosfato biologicamente utilizável, que deve conter, no mínimo, 100 partes de fósforo para cada parte de flúor como margem de segurança na alimentação animal (Mineral..., 1980). A Portaria n²0 da Secretaria Nacional de Defesa Agropecuária (Brasil, 1997) estabelecia que os fosfatos empregados na alimentação animal deveriam apresentar relação mínima de fósforo:flúor (P:F) de 60:1 e limite máximo de flúor de $0,2 \%$ nas misturas minerais. A Portaria $\mathrm{n}^{\circ} 6$ (Brasil, 2000) passou a estabelecer que os fosfatos empregados na alimentação animal apresentem limites máximos de flúor e cálcio de 1 e $20 \%$, respectivamente, com mínimo de $9 \%$ de fósforo nas misturas minerais. As modificações na Portaria no 20 abriram a possibilidade de inclusão do fosfato bruto de rocha na complementação mineral das rações para suínos.

A utilização de fontes de fósforo, alternativa ao fosfato bicálcico normalmente empregado nas rações, tem sido muito discutida pelos nutricionistas de suínos e de outros animais domésticos, pois a legislação sobre o uso dessas na alimentação animal estabelece limites para os teores de fósforo, não levando em consideração a biodisponibilidade e o teor de metais pesados e de outros contaminantes das fontes (Junqueira, 1993; Cavalcante et al., 1996; Veloso et al., 1996a,b). O uso indiscriminado de determinados fosfatos fere o Código de Defesa do Consumidor e prejudica a comercialização dos produtos e a rastreabilidade da cadeia produtiva dos suínos.

Para se avaliar corretamente uma fonte suplementar de fósforo para suínos, deve-se considerar o custo por unidade do elemento, a composição química da fonte, a padronização da composição, a forma química em que o elemento está presente, a granulometria, a solubilidade e o teor de impurezas, além dos riscos da ingestão de produtos oriundos desses animais (Viana, 1985).

Gomes (2002) avaliou a contaminação de fontes de fósforo disponíveis para nutrição animal. Nesse estudo, foram analisadas as seguintes fontes: fosfato bicálcico; fosfato supertriplo de origem nacional e de Marrocos; fosfato monoamônio de origem nacional e rocha fosfática de Catalão. $\mathrm{O}$ fosfato supertriplo importado de Marrocos apresentou maior contaminação, com elevados níveis de cádmio, vanádio e flúor. À exceção do fosfato bicálcico, todas as outras fontes apresentaram contaminação por metais pesados.

Craig et al. (1991) analisaram amostras de fígado e rins de animais de diversas espécies e encontraram contaminação de cádmio e chumbo 
em todas, reiterando o perigo de acúmulo e efeito residual desses elementos.

Este trabalho teve o objetivo de avaliar a composição química e o efeito de diferentes fontes de fósforo sobre a deposição de metais pesados no fígado e músculos de suínos nas fases de crescimento e terminação.

\section{MATERIAL E MÉTODOS}

O experimento foi conduzido no período de novembro de 2001 a maio de 2002.

Para determinação da composição química, foram adquiridas, em estabelecimentos regulares de comércio, 16 fontes de fósforo (sacos fechados): quatro marcas diferentes de fosfato de rocha (rocha Catalão, rocha Araxá, rocha Tapira e rocha Marrocos), três de superfosfato simples (superfosfatos simples 1, 2 e 3 ) e superfosfato triplo (superfosfatos triplos 1, 2 e 3), duas de fosfato bicálcico (fosfatos bicálcicos 1 e 2) e ácido fosfórico (ácido fosfórico industrial e ácido fosfórico PA), uma de fosfato monobicálcico e uma mistura de fontes de fósforo (fosfato Proteindus).

As amostras sólidas foram acondicionadas em embalagens plásticas transparentes, e as amostras líquidas em vidros translúcidos, previamente identificados, com aproximadamente 300 gramas de cada marca.

Foram utilizados 112 leitões com peso médio inicial de 28,68kg, distribuídos em 56 baias, em delineamento experimental de blocos ao acaso, em esquema fatorial $8 \times 2$ (oito fontes de fósforo $\mathrm{x}$ dois sexos) com quatro repetições para machos e três para fêmeas e dois animais por unidade experimental. A distribuição dos animais nos tratamentos foi de acordo com sexo, peso e parentesco.

As dietas foram à base de milho e farelo de soja, sendo o fósforo suplementado por meio dos fosfatos: bicálcico (FBC), monobicálcico (MBC), supertriplo (ST), supersimples (SS), rocha Catalão (ROCHA), ácido fosfórico (AcF), mistura de fontes $[65 \% \mathrm{ST}+30 \% \mathrm{ROCHA}+5 \%$
AcF] (MIST) e dieta-controle (CONT), sem adição de fonte suplementar de fósforo (Tab. 1).

As dietas para as fases de crescimento (30 a $60 \mathrm{~kg})$ e terminação $(60$ a $90 \mathrm{~kg})$ foram formuladas com base nas exigências dos animais (Rostagno et al., 2000). As análises bromatológicas das fontes de fósforo e dos ingredientes das dietas seguiram a metodologia descrita por Silva (1990).

As dietas-controle foram isoprotéicas, com 17,9 e $16,8 \%$ de proteína bruta para as fases de crescimento e terminação, respectivamente, e isocalóricas, com $3400 \mathrm{kcal} / \mathrm{kg}$ de energia digestível. As dietas experimentais, formuladas com base nos valores de fósforo total (FT), foram isofosfóricas, com 0,56 e $0,42 \%$ nas fases de crescimento e terminação, respectivamente.

Os animais foram alojados em baias de crescimento e terminação, sendo os equipamentos, o manejo e o programa profilático semelhantes aos utilizados nas explorações comerciais de suínos.

Ao final do experimento, após jejum de 24 horas, foi abatido um animal por baia, que representou a média de peso do bloco. Foram coletadas e congeladas amostras de aproximadamente 150 gramas do fígado (lóbulo direito) e do músculo longo dorsal (altura da primeira vértebra lombar) para análise de minerais. Depois de cortadas em pedaços pequenos, as amostras foram secas em estufa ventilada a $55^{\circ} \mathrm{C}$ por 72 horas, trituradas em moinho de bola e secas em estufa a $105^{\circ} \mathrm{C}$ por 24 horas. Um grama de amostra seca foi colocado em tubos de digestão, adicionando-se $25 \mathrm{ml}$ de solução nitro-perclórica (1:1). Posteriormente, os tubos foram levados para o bloco digestor, elevando-se lentamente a temperatura a $160^{\circ} \mathrm{C}$ até que a amostra ficasse incolor. Após resfriamento, completou-se o volume para $25 \mathrm{ml}$ com água destilada. A determinação dos teores de minerais foi feita por espectrofotometria de absorção atômica, e a dos teores de fósforo por colorimetria.

A análise estatística das variáveis estudadas foi realizada de acordo com o programa SAS (Statistical..., 1996), e a comparação de médias foi feita pelo teste Student-Newman-Keuls. 
Tabela 1. Composição das dietas experimentais para suínos nas fases de crescimento e terminação

\begin{tabular}{|c|c|c|c|c|c|c|c|c|c|c|c|c|c|c|c|c|}
\hline \multirow{3}{*}{ Ingrediente } & \multicolumn{16}{|c|}{ Dieta experimental } \\
\hline & \multicolumn{8}{|c|}{ Fase de crescimento } & \multicolumn{8}{|c|}{ Fase de terminação } \\
\hline & CONT & FBC & $\mathrm{MBC}$ & ST & SS & ROCHA & MIST & AcF & CONT & FBC & MBC & ST & SS & ROCHA & MIST & $\mathrm{AcF}$ \\
\hline Farelo de soja & 26,24 & 26,24 & 26,24 & 26,24 & 26,24 & 26,24 & 26,24 & 26,24 & 22,08 & 22,08 & 22,08 & 22,08 & 22,08 & 22,08 & 22,08 & 22,08 \\
\hline Milho & 68,00 & 68,00 & 68,00 & 68,00 & 68,00 & 68,00 & 68,00 & 68,00 & 74,40 & 74,40 & 74,40 & 74,40 & 74,40 & 74,40 & 74,40 & 74,40 \\
\hline Óleo de soja & 1,65 & 1,65 & 1,65 & 1,65 & 1,65 & 1,65 & 1,65 & 1,65 & 0,70 & 0,70 & 0,70 & 0,70 & 0,70 & 0,70 & 0,70 & 0,70 \\
\hline Sal & 0,30 & 0,30 & 0,30 & 0,30 & 0,30 & 0,30 & 0,30 & 0,30 & 0,31 & 0,31 & 0,31 & 0,31 & 0,31 & 0,31 & 0,31 & 0,31 \\
\hline Mistura mineral $^{1}$ & 0,10 & 0,10 & 0,10 & 0,10 & 0,10 & 0,10 & 0,10 & 0,10 & 0,10 & 0,10 & 0,10 & 0,10 & 0,10 & 0,10 & 0,10 & 0,10 \\
\hline Mistura vitamínica $^{2}$ & 0,10 & 0,10 & 0,10 & 0,10 & 0,10 & 0,10 & 0,10 & 0,10 & 0,10 & 0,10 & 0,10 & 0,10 & 0,10 & 0,10 & 0,10 & 0,10 \\
\hline Calcário & 1,780 & 0,995 & 1,173 & 1,275 & 0,360 & - & 1,041 & 1,777 & 1,467 & 1,113 & 1,193 & 1,241 & 0,820 & 0,664 & 1,135 & 1,468 \\
\hline Fosfato bicálcico & - & 1,280 & - & - & - & - & - & - & - & 0,58 & - & - & - & - & - & - \\
\hline Fosfato monobicálcico & & & 1,180 & & & & & & & & 0,535 & & & & & \\
\hline Superfosfato triplo & - & - & - & 1,160 & - & - & 0,845 & - & - & - & & 0,525 & - & - & 0,383 & - \\
\hline Superfosfato simples & - & - & - & - & 3,140 & - & - & - & - & - & & - & 1,43 & - & - & - \\
\hline Fosfato rocha Catalão & - & - & - & - & - & 1,880 & 0,390 & - & - & - & & - & - & 0,85 & 0,177 & - \\
\hline Ácido fosfórico & - & - & - & - & - & - & 0,065 & 1,023 & - & - & & - & - & - & 0,030 & 0,465 \\
\hline Areia lavada (inerte qsp) & 1,720 & 1,225 & 1,147 & 1,065 & - & 1,620 & 1,259 & 0,700 & 0,783 & 0,557 & 0,522 & 0,484 & - & 0,736 & 0,525 & 0,317 \\
\hline Total & 100 & 100 & 100 & 100 & 100 & 100 & 100 & 100 & 100 & 100 & 100 & 100 & 100 & 100 & 100 & 100 \\
\hline \multicolumn{17}{|l|}{ Composição química $^{3}$} \\
\hline Proteína $(\%)$ & 17,90 & 17,90 & 17,90 & 17,90 & 17,90 & 17,90 & 17,90 & 17,90 & 16,50 & 16,50 & 16,502 & 16,50 & 16,50 & 16,50 & 16,50 & 16,50 \\
\hline Fósforo total (\%) & 0,32 & 0,560 & 0,560 & 0,560 & 0,560 & 0,560 & 0,560 & 0,560 & 0,310 & 0,420 & 0,420 & 0,420 & 0,420 & 0,420 & 0,420 & 0,420 \\
\hline Cálcio (\%) & 0,780 & 0,780 & 0,780 & 0,780 & 0,780 & 0,780 & 0,780 & 0,780 & 0,651 & 0,651 & 0,651 & 0,651 & 0,651 & 0,651 & 0,651 & 0,651 \\
\hline Lisina total (\%) & 0,980 & 0,980 & 0,980 & 0,980 & 0,980 & 0,980 & 0,980 & 0,980 & 0,840 & 0,840 & 0,840 & 0,840 & 0,840 & 0,840 & 0,840 & 0,840 \\
\hline Metionina (\%) & 0,287 & 0,287 & 0,287 & 0,287 & 0,287 & 0,287 & 0,287 & 0,287 & 0,270 & 0,270 & 0,270 & 0,270 & 0,270 & 0,270 & 0,270 & 0,270 \\
\hline Treonina (\%) & 0,693 & 0,693 & 0,693 & 0,693 & 0,693 & 0,693 & 0,693 & 0,693 & 0,639 & 0,639 & 0,639 & 0,639 & 0,639 & 0,639 & 0,639 & 0,639 \\
\hline Triptofano (\%) & 0,212 & 0,212 & 0,212 & 0,212 & 0,212 & 0,212 & 0,212 & 0,212 & 0,188 & 0,188 & 0,188 & 0,188 & 0,188 & 0,188 & 0,188 & 0,188 \\
\hline
\end{tabular}

CONT: dieta controle; FBC: fosfato bicálcico; MBC: fosfato monobicálcico; ST: superfosfato triplo; SS: superfosfato simples; ROCHA: fosfato de rocha Catalão; MIST: mistura de fontes; AcF: ácido fosfórico.

Conteúdo $\mathrm{kg} \cdot 100 \mathrm{~g} \mathrm{Fe} ; 10 \mathrm{~g} \mathrm{Cu} ; 1 \mathrm{~g} \mathrm{Co} ; 40 \mathrm{~g} \mathrm{Mn} ; 100 \mathrm{~g} \mathrm{Zn} ; 0,3 \mathrm{~g} \mathrm{Se} ; 1,5 \mathrm{~g} \mathrm{I} ; 1.000 \mathrm{~g}$ excipiente QSP $1.000 \mathrm{~g}$

${ }^{2}$ Conteúdo/kg: vit A - 6.000.000UI; $\mathrm{D}_{3}-1.500 .000 \mathrm{UI}$; E - 15.000UI; $\mathrm{B}_{1}-1,35 \mathrm{~g} ; \mathrm{B}_{2}-4 \mathrm{~g} ; \mathrm{B}_{6}-2 \mathrm{~g}$; ácido pantotênico - 9,35g; vit $\mathrm{K}_{3}$ - 1,5g; ácido nicotínico - 20,0g; vit $\mathrm{B}_{12}$ - 20,0g; ácido fólico - 0,6g; biotina $0,08 \mathrm{~g}$; excipiente QSP - 1.000g.

${ }^{3}$ Composição calculada conforme Rostagno et al. (2000). 


\section{RESULTADOS E DISCUSSÃO}

Os dados de composição química das fontes de fósforo encontram-se na Tab. 2.

$\mathrm{O}$ fosfato de rocha Marrocos apresentou menor quantidade de $\mathrm{Fe}$ e de $\mathrm{Mn}$ e maior de $\mathrm{Pb}, \mathrm{Cr}$ e $\mathrm{Cd}$ que os fosfatos Catalão, Araxá e Tapira. O fosfato bicálcico 1 apresentou alto nível de magnésio, o que pode provocar diminuição na biodisponibilidade de $\mathrm{P}$ para suínos. Houve grande variação na composição de metais pesados entre as marcas comerciais de superfosfatos simples e triplo. $\mathrm{O}$ fosfato monobicálcico apresentou baixa contaminação por metais pesados, enquanto o ácido fosfórico industrial teve sua composição superior à do ácido fosfórico PA.

Tabela 2. Composição química das fontes de fósforo fornecidas para suínos nas fases de crescimento e terminação

\begin{tabular}{|c|c|c|c|c|c|c|c|c|c|c|c|}
\hline \multirow[b]{2}{*}{ Fonte de fósforo } & \multicolumn{11}{|c|}{ Composição química } \\
\hline & $\begin{array}{c}\mathrm{P} \\
(\%) \\
\end{array}$ & $\begin{array}{c}\mathrm{Ca} \\
(\%) \\
\end{array}$ & $\begin{array}{l}\mathrm{Mg} \\
(\%) \\
\end{array}$ & $\begin{array}{c}\mathrm{Mn} \\
\mathrm{Ppm}\end{array}$ & $\begin{array}{c}\mathrm{Zn} \\
\mathrm{ppm}\end{array}$ & $\begin{array}{c}\mathrm{Fe} \\
\mathrm{ppm}\end{array}$ & $\begin{array}{c}\mathrm{Cu} \\
\mathrm{ppm}\end{array}$ & $\begin{array}{c}\mathrm{Pb} \\
\mathrm{ppm}\end{array}$ & $\begin{array}{c}\mathrm{Ni} \\
\mathrm{ppm}\end{array}$ & $\begin{array}{c}\mathrm{Cr} \\
\mathrm{ppm}\end{array}$ & $\begin{array}{r}\mathrm{Cd} \\
\mathrm{ppm}\end{array}$ \\
\hline Rocha Catalão * & 12,73 & 36,00 & 0,81 & 405,0 & 36,7 & 8486,0 & 14,9 & 37,1 & 35,17 & 9,12 & 2,87 \\
\hline Rocha Araxá & 14,35 & 29,82 & 0,54 & 52,5 & 208,8 & 6463,5 & 11,1 & 39,1 & 40,58 & 13,49 & 3,73 \\
\hline Rocha Tapira & 15,34 & 31,11 & 0,50 & 31,3 & 229,1 & 5041,0 & 5,5 & 39,4 & 23,30 & 7,84 & 3,95 \\
\hline Rocha Marrocos & 12,41 & 32,31 & 0,51 & 3,1 & 161,9 & 772,5 & 17,5 & 41,6 & 32,56 & 76,32 & 12,35 \\
\hline Superfosfato simples * & 7,62 & 17,20 & 0,57 & 46,3 & 123,0 & 9026,5 & 16,7 & 20,7 & 33,68 & 23,06 & 4,03 \\
\hline Superfosfato simples & 9,32 & 23,83 & 0,39 & 30,3 & 149,7 & 7232,5 & 11,6 & 17,4 & 26,08 & 14,50 & 2,52 \\
\hline Superfosfato simples & 7,70 & 24,29 & 0,43 & 31,8 & 154,5 & 4770,5 & 13,4 & 18,7 & 26,29 & 14,80 & 2,37 \\
\hline Fosfato bicálcico * & 18,66 & 23,25 & 1,34 & 64,0 & 10,9 & 4091,5 & 11,5 & 20,8 & 14,74 & 8,91 & 2,67 \\
\hline Fosfato bicálcico & 18,60 & 25,70 & 0,48 & 76,8 & 38,3 & 3953,5 & 103,9 & 22,1 & 26,01 & 8,35 & 3,08 \\
\hline Fosfato Proteindus & 15,59 & 31,07 & 0,81 & 19,0 & 3,8 & 912,5 & 139,6 & 48,5 & 22,17 & 5,88 & 3,30 \\
\hline Superfosfato triplo * & 20,63 & 16,46 & 0,64 & 2,4 & 488,4 & 1038,0 & 24,4 & 22,2 & 32,18 & 353,5 & 14,15 \\
\hline Superfosfato triplo & 20,09 & 20,19 & 0,71 & 36,8 & 16,6 & 5096,5 & 11,0 & 17,6 & 14,19 & 8,58 & 2,18 \\
\hline Superfosfato triplo & 20,38 & 13,98 & 0,78 & 39,4 & 13,2 & 3759,0 & 6,7 & 17,1 & 9,58 & 4,59 & 1,95 \\
\hline Fosfato monobicálcico $*$ & 20,29 & 19,50 & 0,81 & 36,3 & 4,6 & 1431,5 & 7,8 & 18,5 & 9,57 & 5,92 & 2,04 \\
\hline Ácido fosfórico industrial * & 23,38 & 0,00 & 0,56 & 29,7 & 7,3 & 893,0 & 4,9 & 13,6 & 5,11 & 8,07 & 2,06 \\
\hline Ácido fosfórico PA & 19,68 & 0,00 & 0,37 & 0,7 & 0,6 & 31,3 & 1,8 & 12,6 & 0,53 & 3,67 & 2,00 \\
\hline
\end{tabular}

Observou-se valor elevado de metais pesados nas fontes menos elaboradas (fosfato de rocha e superfosfatos simples e triplo). Segundo Ballio (1986), com relação ao teor de metais pesados, as fontes de fosfato sofrem variação em função das diferentes rochas fosfáticas encontradas na natureza, o que interfere nos produtos delas derivados. O teor desses minerais nas rochas brasileiras é muito inferior ao encontrado nas rochas fosfáticas estrangeiras, por serem de origem ígnea, contrastando com a origem sedimentar em outros países.

As duas marcas de fosfato bicálcico avaliadas apresentaram níveis superiores de $\mathrm{Cu}$ e $\mathrm{Pb}$ e inferiores de $\mathrm{Mn}, \mathrm{Zn}, \mathrm{Fe}, \mathrm{Cd}, \mathrm{Cr}$ e $\mathrm{Ni}$ aos encontrados por Lima et al. (1995), que trabalharam com cinco marcas de fosfato bicálcico produzidas no Brasil e duas produzidas nos Estados Unidos.
Segundo Borges et al. (1997), elementos como $\mathrm{Mg}, \mathrm{Fe}, \mathrm{Al}, \mathrm{Mn}$ e metais pesados podem diminuir a absorção de fósforo das fontes em razão da formação de fosfatos insolúveis ou devido à inter-relação entre os minerais na absorção e na corrente sangüínea.

Charter et al. (1993) analisaram 24 amostras de superfosfato triplo (ST) vendidas nos Estados Unidos e encontraram média de $8,1 \mathrm{mg} / \mathrm{kg}$ para Cd. Uma marca comercial de ST analisada no presente trabalho continha $14,15 \mathrm{mg} / \mathrm{kg}$, indicando que o ST foi produzido com rocha fosfática importada (Ballio, 1986; Lopes et al., 1997; Gomes, 2002), pois as rochas brasileiras apresentam baixo teor de $\mathrm{Cd}$. As fontes de fósforo analisadas neste trabalho continham de 12,6 a 48,5mg/kg de $\mathrm{Pb}$. Balio (1986) encontrou valores entre 12 e $36 \mathrm{mg} / \mathrm{kg}$ em diferentes tipos de fosfatos analisados.

Os teores de minerais verificados no fígado de 
suínos nas fases de crescimento e terminação, em função das dietas experimentais, encontram-se na Tab. 3.

As fontes de fósforo não influenciaram $(\mathrm{P}>0,05)$ os teores de $\mathrm{Mn}, \mathrm{Ni}, \mathrm{Cr}$ e $\mathrm{Cd}$ no fígado dos animais, porém influenciaram $(\mathrm{P}<0,05)$ os de $\mathrm{Zn}$, $\mathrm{Fe}, \mathrm{Cu}$ e $\mathrm{Pb}$. O teor de $\mathrm{Zn}$ foi maior $(\mathrm{P}<0,05)$ no fígado dos animais que consumiram dieta CONT.

Tabela 3.Teores de manganês $(\mathrm{Mn})$, zinco $(\mathrm{Zn})$, ferro $(\mathrm{Fe})$, cobre $(\mathrm{Cu})$, chumbo $(\mathrm{Pb})$, níquel $(\mathrm{Ni})$, cromo $(\mathrm{Cr})$ e cádmio $(\mathrm{Cd})$ no fígado de suínos nas fases de crescimento e terminação, de acordo com os tratamentos

\begin{tabular}{|c|c|c|c|c|c|c|c|c|c|}
\hline \multirow[b]{2}{*}{ Tratamento } & \multirow[b]{2}{*}{$\begin{array}{l}\text { MS } \\
(\%)\end{array}$} & \multicolumn{7}{|c|}{ Mineral } & \multirow[b]{2}{*}{$\begin{array}{c}\mathrm{Cd} \\
(\mathrm{mg} / \mathrm{kg})\end{array}$} \\
\hline & & $\begin{array}{c}\mathrm{Mn} \\
(\mathrm{mg} / \mathrm{kg})\end{array}$ & $\begin{array}{c}\mathrm{Zn} \\
(\mathrm{mg} / \mathrm{kg})\end{array}$ & $\begin{array}{c}\mathrm{Fe} \\
(\mathrm{mg} / \mathrm{kg})\end{array}$ & $\begin{array}{c}\mathrm{Cu} \\
(\mathrm{mg} / \mathrm{kg})\end{array}$ & $\begin{array}{c}\mathrm{Pb} \\
(\mathrm{mg} / \mathrm{kg})\end{array}$ & $\begin{array}{c}\mathrm{Ni} \\
(\mathrm{mg} / \mathrm{kg})\end{array}$ & $\begin{array}{c}\mathrm{Cr} \\
(\mathrm{mg} / \mathrm{kg})\end{array}$ & \\
\hline CONT & 28,13 & 7,11 & $253,15 a$ & $398,8 \mathrm{abc}$ & $16,37 \mathrm{a}$ & $2,53 a$ & 0,040 & 4,76 & $0,214 b$ \\
\hline FBC & 28,18 & 7,38 & $198,10 b$ & $435,4 \mathrm{ab}$ & $14,04 \mathrm{ab}$ & $1,78 \mathrm{abc}$ & 0,052 & 4,46 & $0,240 \mathrm{~b}$ \\
\hline $\mathrm{MBC}$ & 27,84 & 6,87 & $159,03 b$ & $272,3 c$ & $12,54 b$ & $1,58 b c$ & 0,114 & 4,62 & $0,200 \mathrm{~b}$ \\
\hline ST & 28,26 & 6,39 & $190,97 b$ & $402,3 \mathrm{abc}$ & $13,73 \mathrm{ab}$ & $1,76 a b c$ & 0,027 & 4,59 & $0,323 a$ \\
\hline $\mathrm{SS}$ & 27,61 & 6,01 & $168,19 b$ & $486,2 \mathrm{a}$ & $13,02 b$ & $1,43 \mathrm{c}$ & 0,00 & 3,95 & $0,215 b$ \\
\hline ROCHA & 27,70 & 6,38 & $193,49 b$ & $436,8 \mathrm{ab}$ & $16,47 \mathrm{a}$ & $2,03 \mathrm{abc}$ & 0,00 & 4,12 & $0,294 b$ \\
\hline MIST & 26,85 & 5,83 & $179,18 b$ & $299,4 b c$ & $12,06 \mathrm{~b}$ & $1,82 \mathrm{abc}$ & 0,00 & 4,56 & $0,366 \mathrm{a}$ \\
\hline $\mathrm{AcF}$ & 28,27 & 6,85 & $159,55 b$ & $487,4 a$ & $11,55 b$ & $2,37 \mathrm{ab}$ & 0,056 & 4,25 & $0,251 b$ \\
\hline CV $(\%)$ & & 13,85 & 14,75 & 23,70 & 15,70 & 25,88 & 356,4 & 15,05 & 55,26 \\
\hline
\end{tabular}

CONT: dieta controle; FBC: fosfato bicálcico; MBC: fosfato monobicálcico; ST: superfosfato triplo; SS: superfosfato simples; ROCHA: fosfato de rocha Catalão; MIST: mistura de fontes; AcF: ácido fosfórico. MS: matéria seca.

Médias seguidas de letras distintas na coluna diferem entre si pelo teste Student-Newman-Keuls $(\mathrm{P}<0,05)$.

$\mathrm{O}$ teor de $\mathrm{Fe}$ no fígado foi maior $(\mathrm{P}<0,05)$ nos animais que consumiram as dietas $\mathrm{SS}$ e $\mathrm{AcF}$, não diferindo daqueles que consumiram CONT, FBC, ST, ROCHA e MIST. O menor valor $(\mathrm{P}<0,05)$ foi observado nos animais que consumiram MBC. O acúmulo de $\mathrm{Cu}$ no fígado foi maior nos animais que consumiram CONT e ROCHA, não diferindo dos resultados obtidos com aqueles que consumiram FBC e ST. Os menores valores $(\mathrm{P}<0,05)$ foram observados nos animais que consumiram MBC, SS, MIST e AcF.

$\mathrm{O}$ acúmulo de $\mathrm{Pb}$ no fígado foi maior $(\mathrm{P}<0,05)$ nos animais que consumiram dieta $\mathrm{CONT}$, não diferindo $(\mathrm{P}>0,05)$ dos valores encontrados naqueles que consumiram $\mathrm{FBC}, \mathrm{MBC}, \mathrm{ST}$, ROCHA, MIST e AcF. O menor valor $(\mathrm{P}<0,05)$ foi obtido nos animais que consumiram $\mathrm{SS}$.

Os animais que consumiram dieta CONT, deficiente em $\mathrm{P}$, apresentaram sintomas de "apetite depravado", manifestado pelo ato de roer e comer elementos estranhos à sua dieta, como cocho, madeira, torneiras, arames, terra etc., o que pode explicar o maior teor de $\mathrm{Zn}, \mathrm{Cu}$ e $\mathrm{Pb}$ no fígado desses animais.

Os animais que consumiram as dietas ST e MIST apresentaram $(\mathrm{P}<0,05)$ teores elevados de $\mathrm{Cd}$ no fígado, provavelmente em conseqüência do alto nível do mineral encontrado na composição do superfosfato triplo 1 (Tab. 2).

De acordo com o Plano Nacional de Controle de Resíduos Biológicos em Produtos de Origem Animal (PNCRB), proposto por Brasil (1999), observou-se que, no fígado dos animais que consumiram as dietas CONT, ROCHA e AcF, os limites de tolerância para $\mathrm{Pb}(2 \mathrm{mg} / \mathrm{kg})$ foram ultrapassados. O limite de cádmio $(1 \mathrm{mg} / \mathrm{kg})$ não foi ultrapassado em nenhum dos tratamentos.

A deposição de metais pesados no organismo animal não depende exclusivamente da concentração na fonte, mas também do equilíbrio metabólico dos demais minerais que são absorvidos (Mineral..., 1980; Nutrient..., 1988). Em razão do desequilíbrio entre os minerais, ocasionado pelo fosfato de rocha ou ST, os mecanismos de absorção e excreção dos metais pesados são comprometidos, gerando maior acúmulo deles no fígado.

Segundo Stuart e Oehme (1982), a toxicidade do Pb, proveniente de alimentos, pode gerar quadros de abortamento em suínos, causando prejuízo reprodutivo e econômico. A ingestão moderada de 
cádmio pelos animais pode provocar anemia, desmineralização óssea e lesões hepáticas (Mineral..., 1980).
Os teores dos minerais nos músculos de suínos nas fases de crescimento e terminação, em função das dietas experimentais, encontram-se na Tab. 4.

Tabela 4. Teores de fósforo $(\mathrm{P})$, cálcio $(\mathrm{Ca})$, magnésio $(\mathrm{Mg})$, ferro $(\mathrm{Fe})$, zinco $(\mathrm{Zn})$, cobre $(\mathrm{Cu})$, chumbo $(\mathrm{Pb})$, níquel $(\mathrm{Ni})$, manganês $(\mathrm{Mn})$, cromo $(\mathrm{Cr})$ e cádmio $(\mathrm{Cd})$ no músculo de suínos nas fases de crescimento e terminação, de acordo com os tratamentos

\begin{tabular}{lccccccccc}
\hline \multirow{2}{*}{ Tratamento } & \multicolumn{10}{c}{ MS } & \begin{tabular}{c}
$\mathrm{P}$ \\
\cline { 2 - 9 }
\end{tabular} & $\begin{array}{c}\mathrm{Ca} \\
(\%)\end{array}$ & $\begin{array}{c}\mathrm{Mg} \\
(\mathrm{mg} / \mathrm{kg})\end{array}$ & $\begin{array}{c}\mathrm{Fe} \\
(\mathrm{mg} / \mathrm{kg})\end{array}$ & $\begin{array}{c}\mathrm{Zn} \\
(\mathrm{mg} / \mathrm{kg})\end{array}$ & $\begin{array}{c}\mathrm{Cu} \\
(\mathrm{mg} / \mathrm{kg})\end{array}$ & $\begin{array}{c}\mathrm{Pb} \text { e Cd } \\
(\mathrm{mg} / \mathrm{kg})\end{array}$ & $\begin{array}{c}\mathrm{Ni}, \mathrm{Mn} \text { e Cr } \\
(\mathrm{mg} / \mathrm{kg})\end{array}$ \\
\hline CONT & 28,51 & 0,891 & 138,52 & 872,71 & $46,90 \mathrm{ab}$ & 57,94 & $3,23 \mathrm{ab}$ & $<0,01$ & $<0,1$ \\
FBC & 28,92 & 0,862 & 133,57 & 862,79 & $42,40 \mathrm{ab}$ & 59,95 & $2,88 \mathrm{~b}$ & $<0,01$ & $<0,1$ \\
MBC & 27,96 & 0,922 & 128,37 & 879,82 & $48,80 \mathrm{ab}$ & 61,39 & $3,13 \mathrm{ab}$ & $<0,01$ & $<0,1$ \\
ST & 28,45 & 0,906 & 148,80 & 876,27 & $50,24 \mathrm{a}$ & 63,72 & $3,36 \mathrm{a}$ & $<0,01$ & $<0,1$ \\
SS & 28,03 & 0,863 & 128,79 & 852,30 & $47,56 \mathrm{ab}$ & 59,70 & $3,32 \mathrm{ab}$ & $<0,01$ & $<0,1$ \\
ROCHA & 29,11 & 0,881 & 127,99 & 868,16 & $48,93 \mathrm{ab}$ & 62,75 & $3,12 \mathrm{ab}$ & $<0,01$ & $<0,1$ \\
MIST & 27,57 & 0,930 & 138,87 & 862,92 & $41,07 \mathrm{~b}$ & 66,02 & $3,38 \mathrm{a}$ & $<0,01$ & $<0,1$ \\
AcF & 27,88 & 0,912 & 125,36 & 878,95 & $42,44 \mathrm{ab}$ & 61,85 & $2,97 \mathrm{ab}$ & $<0,01$ & $<0,1$ \\
CV (\%) & & 5,44 & 10,98 & 3,06 & 11,82 & 8,70 & 8,80 & & \\
\hline
\end{tabular}

CONT: dieta controle; FBC: fosfato bicálcico; MBC: fosfato monobicálcico; ST: superfosfato triplo; SS: superfosfato simples; ROCHA: fosfato de rocha Catalão; MIST: mistura de fontes; AcF: ácido fosfórico. MS: matéria seca.

Médias seguidas de letras distintas na coluna diferem entre si pelo teste Student-Newman-Keuls $(\mathrm{P}<0,05)$.

As fontes de fósforo não influenciaram $(\mathrm{P}>0,05)$ os teores de $\mathrm{P}, \mathrm{Ca}, \mathrm{Mg}$ e $\mathrm{Zn}$ nos músculos dos animais, mas $\operatorname{sim}(\mathrm{P}<0,05)$ os de $\mathrm{Fe}$ e $\mathrm{Cu}$. O teor de $\mathrm{Fe}$ foi maior $(\mathrm{P}<0,05)$ nos músculos dos animais que consumiram dieta ST em relação ao dos animais do MIST, não diferindo $(\mathrm{P}>0,05)$ do teor encontrado nos que consumiram CONT, FBC, MBC, SS, ROCHA e AcF. O menor valor $(\mathrm{P}<0,05)$ foi observado nos animais que consumiram MIST. O teor de $\mathrm{Cu}$ foi maior $(\mathrm{P}<0,05)$ nos músculos dos animais que consumiram ST e MIST em relação a $\mathrm{FBC}$, não diferindo $(\mathrm{P}>0,05)$ daqueles que consumiram CONT, MBC, SS, ROCHA e aos do AcF. O menor teor de $\mathrm{Cu}$ nos músculos $(\mathrm{P}<0,05)$ foi observado nos animais que consumiram FBC.

Os teores mais elevados de $\mathrm{Cu}$ nos músculos dos animais que consumiram ST e MIST sugerem que o excesso desse mineral (Tab. 2) provavelmente foi depositado neles.

De acordo com PNCRB, proposto por Brasil (1999), nenhuma das amostras de músculo analisadas ultrapassou os limites de tolerância de $\mathrm{Pb}$ e Cd. Lopes et al. (2000) e Oliveira et al. (2000), ao trabalharem com bovinos de corte, avaliaram os efeitos da presença de metais pesados nas massas musculares e concluíram que a mistura mineral que tem como base o superfosfato triplo produzido a partir da rocha Tapira ou o fosfato bicálcico não oferece risco para a saúde humana ou animal.

Observou-se, neste trabalho, que os metais pesados apresentaram máxima deposição no fígado. Portanto, o uso de fontes alternativas de fósforo ou suplementos minerais contaminados por metais pesados, ainda que em níveis aceitáveis, pode ocasionar maior acúmulo nas vísceras dos animais, atingindo a cadeia trófica alimentar e, conseqüentemente, o homem, por meio do consumo de produtos e subprodutos de origem animal, o que representa potencial risco à saúde humana.

\section{CONCLUSÕES}

A utilização de fontes alternativas de fósforo menos elaboradas influenciou a deposição de minerais no fígado e nos músculos dos suínos.

\section{REFERÊNCIAS BIBLIOGRÁFICAS}

BALLIO, L.A.C. Distribuição de microelementos e metais pesados nas rochas nacionais [s.1.]. Instituto Brasileiro do Fosfato, 1986. 10p. 
BORGES, F.M.O.; FURTADO, M.A.O.; VELOSO, J.A. et al. Disponibilidade do fósforo de fontes inorgânicas para frangos de corte. Arq. Bras. Med. Vet. Zootec., v.49, p.639-647, 1997.

BRASIL. Ministério da Agricultura. Instrução Normativa N. ${ }^{\circ}$ 3, de 22 de janeiro de 1999 reeditou o PNCRB, alterando as normas relativas ao controle de resíduos na carne. Brasília, Jan. 1999.

BRASIL. Secretaria Nacional de Defesa Agropecuária. Portaria n.33 de 22 de abril de 1997. Diário Oficial da União, Brasília, 6 de junho de 1997.

BRASIL. Secretaria Nacional de Defesa Agropecuária. Portaria n.6 de c. Diário Oficial da União, Brasília, 4 de fevereiro de 2000.

CAVALCANTE, S.G.; VELOSO, J.A.F.; FERREIRA, W.M. et al. Avaliação química dos tecidos comestíveis de suínos alimentados com quatro fosfatos de rocha. In: REUNIÃO ANUAL DA SOCIEDADE BRASILEIRA DE ZOOTECNIA, 33., Fortaleza, CE. Anais... Fortaleza: SBZ, 1996. v.1, p.163-164.

CHARTER, R.A.; TABATABAI, M.A.; SCHAFER, J.W. Metal contents of fertilizers marketed in Iowa. Soil Sci. Plant Anal., v.24, p.961-972, 1993.

CRAIG, D.C.S.; CHAN, W.; SASCHENBRECKER, P.W. Multielement concentrations in liver and kidney tissues from five species of canadian slaughter animals. J. Assoc. Anal. Chem., v.74, p.587-591, 1991.

GOMES, G.P. Avaliação quantitativa de xenobióticos em fontes de fósforo para nutrição mineral de bovinos. 2002. 64f. Dissertação (Mestrado em Ciência Animal) - Universidade Estadual de Londrina, Londrina, PR.

JUNQUEIRA, O.M. Metais pesados contaminam carne. Avic. Suin. Industr., n.3, p.27-29, 1993.

LIMA, F.R.; MENDONÇA, C.X.; ALVAREZ, J.C. et al. Chemical and physical evaluations of commercial dicalcium phosphate as source of phosphorus in animal nutrition. Poult. Sci., v.74, p.1659-1670, 1995.

LOPES, H.O.S.; PEREIRA, G.; PEREIRA, E.A. Avaliação dos níveis de metais pesados e do flúor em amostras de fosfato bicálcico e superfosfato triplo para nutrição animal. In: REUNIÃO ANUAL DA SOCIEDADE BRASILEIRA DE ZOOTECNIA, 34., Juiz de Fora, 1997. Anais... Juiz de Fora, SBZ, 1997. p.462-464.

LOPES, H.O.S.; PEREIRA, L.G.R.; PEREIRA, E.A. et al. Avaliação dos níveis de flúor, metais pesados e outros minerais em tecidos de bovinos que receberam superfosfato triplo. In: REUNIÃO ANUAL DA SOCIEDADE BRASILEIRA DE ZOOTECNIA, 37.,
2000, Viçosa. Anais... Viçosa: SBZ, 2000. CD ROM.

LOPES, J.B. Avaliação da absorção real e das perdas endógenas de fósforo para suínos pela técnica de diluição isotópica. 1998. 87f. Tese (Doutorado) Centro de Energia Nuclear na Agricultura, Universidade de São Paulo, Piracicaba, SP.

MINERAL tolerance of domestic animals. Washington, DC: National Academy of Sciences, 1980. 577p.

NUTRIENT requirements of swine. 9.ed. Washington: National Academy of Science, 1988. 64p.

OLIVEIRA, A.L.; LOPES, H.O.S.; PEREIRA, E.A. et al. Avaliação de diferentes fontes de fósforo sobre os rendimentos ao abate e níveis de metais pesados em bovinos de corte. In: REUNIÃO ANUAL DA SOCIEDADE BRASILEIRA DE ZOOTECNIA, 37. 2000, Viçosa, MG. Anais... Viçosa, SBZ, 2000. CD ROM.

PONPE, G.J.; PREVENDAR, C. Cadmium in tissues of roe deer (Capreolus capreolus). Veterinarski Arhiv. Zagreb, v.72, p.303-310. 2002.

ROSTAGNO, H.S.; ALBINO, L.F.T.; DONZELE, J.L. et al. Tabelas brasileira para aves e suínos; composição de alimentos e exigências nutricionais. In: REUNIÃO ANUAL DA SOCIEDADE BRASILEIRA DE ZOOTECNIA, 37., 2000, Viçosa, MG. Anais... Viçosa, SBZ, 2000. p.141.

SILVA, D.J. Análise de alimentos (Métodos químicos e biológicos). Viçosa, MG: UFV, Imprensa Universitária, 1990. 165p.

STATISTICAL analysis system - SAS. System for Windows, release 6.12. Cary, NC: 01 CD-ROM, 1996.

STUART, L.D.; OEHME, F.V. Environmental factors bovine and porcine abortion. Vet. Human Toxicol., v.24, p.435-441, 1982.

VELOSO, J.A.F.; CAVALCANTE, S.G.; HOSSAIN, S.M. et al. Disponibilidade biológica de fósforo de cinco fontes alternativas de fósforo para leitões recémdesmamados. Arq. Bras. Med. Vet. Zootec., v.48, p.451-461, 1996a.

VELOSO, J.A.F.; FURTADO, M.A.O.; BORGES, F.M.O. et al. Biodisponibilidade de fósforo para aves e suínos. Teores de enzimas ósseas e atividade da fosfatase alcalina. Arq. Bras. Med. Vet. Zootec., v.48, p.575-593, 1996b.

VIANA, J.A.F. Fontes de sais minerais para bovinos e o desafio de suplementos de fósforo no Brasil. In: SIMPÓSIO SOBRE NUTRIÇÃO DE BOVINOS, 1985, Piracicaba. Anais... Piracicaba- SP, 1985. p.4766. 